\title{
INTERACTION OF RESEARCH AND SUBJECTS IN SOCIAL INTERVENTION STUDIES
}

\author{
Charles A. Metzner \\ Department of Medical Care Organization \\ School of Public Health \\ The University of Michigan \\ Ann Arbor, Michigan 48104
}

Since the literature on studies of studies is not rich, it appeared that to achieve any attempt at a rounded viewpoint another base was necessary. For the last twenty years I have worked in a school of public health, an area practicing intervention long before I came on the scene. However, my entry as a psychologist and the hiring of many colleagues from the social sciences came about, seemingly, as a result of a shift in relationships between health professionals and their publics. Apparently as an aftermath of the Great Depression and the Roosevelt Revolution, members of the public were unwilling to accept commands from experts. At any rate, we were asked to give courses in how to reach the unreached, on the social bases of health behavior, and in general on how to entice people into health programs. This is an interesting sequel to the rise of organized public health activities associated with the social ferment around 1850.

I mention this not only for whatever interest it may have, but also as a warning concerning the levels of certainty of much of what I have to say, which will be much like that above, to be taken with much salt. I am not operating on bedrock or with mathematical generalizations of well-founded data. Nonetheless, there is a rich body of experience and lore that can be useful as caution and hypothesis, and Thucydides' statement about the utility of history may well apply. Many things that have happened may recur, but often they shouldn't.

What I am dealing with is the social process involved among practitioner, research worker, and a public in the course of studying intervention. It could be recast into the form of Holmes or Mead, discussing their perceptions of our perceptions of their perceptions because it does involve the peculiarities of looking over one's own shoulder. I am sorry that I can't give a page of structural equations involving these game theoretic feedback processes and I have not included a one-page systems diagram, although I don't apologize too heartily.

My favorite null model of cooperative unhelpful intervention is that of two people at both ends of a two-way switch system. As one is about to turn on the light, the other responds by also flipping his switch, and we have a vivid realization of the equation $1+1=0$. I have not analyzed this in detail nor extended it to the three-party situations we are considering. This is a complex process involving a high degree of self-consciousness about others. Even theologians have trouble with this, and we are far from a theory of involvement. If I can intervene in your thinking and thus contribute to successful intervention, I would be happy in the conviction that you had contributed to their happiness. Much of what I say is personal experience, and I hope it isn't overly hortatory. This, however, is another one of the dangers of intervention. If you are repelled by it, try to turn it to account by not getting caught doing it yourself.

Recently, studies of medical practice, which is intervention of the first order, have indicated problems that are worthy of note. Many of these problems arose because the intervention was considered to be purely biological, and this may 
be an initial warning: social problems do not come in academic departmental packets. Psychologists need to remember that people have to earn a living, just as other social scientists have to consider that demand is not ad hoc and that people adjust to unmet need, so that insured services are not immediately demanded. ${ }^{1}$ Among the problems of the patient-physician relation is the translation of the technicalities of medicine into lay language. It is not always done well. Numerous violations of instructions concerning patient behavior have been documented, and the key here appears to be an explanation of why a recommendation is made. ${ }^{2}$ It was found that patients learned more about their heart conditions from newspaper accounts of a President than from their own physicians. ${ }^{3}$ Mutual understanding may not be sufficient for easy social relations, but they do appear necessary. To sharpen the parallel, let me ask about the questions in "research instruments" that depend on rare vocabulary or are otherwise unclear, and indicate the difficulty in using "scales" developed from college students for other populations. ${ }^{4}$ A foolish answer to a foolish question should not be used to so code a respondent. Attempting to understand our fellow social scientists' explanations of poverty, delinquency, and other phenomena in which we wish to intervene will give us a clue to others, and to the rich diversity of human activity.

From here it is a short step to what appears to be the greatest problem in evaluation work in public health, with numerous ramifications that can entrap anyone. This is the fact that they, like all social interventionists from Lady Bountiful to Lyndon Johnson, are doing good; they are helping people. This makes it difficult to find out exactly what is being done and requires the highest degree of imaginative skill in hypothesization to develop the possible bases of evaluation by the subjects. An objective may be good and a procedure horrible, and what is sauce for the goose may or may not be sauce for the gander, but may well not be for sheep or goats. It is a commonplace among social scientists that ours is a pluralistic society with differentiated persons, but it is a commonplace of politicians and other practitioners that all Americans have common values. It is, however, difficult to devise testable hypotheses about liberty, justice, and motherhood. The assumption of a common good is so general and so noxious that perhaps the Golden Rule itself needs restatement. Certainly this is one of the complaints of blacks against white education, white English, and white intervention altogether.

Since this is very general, I will illustrate the specific effects on research from a study we did on a tuberculosis $x$-ray program. 5 The very statistic was in question, and still unanswered issues of nonlinearities in measurement were raised. Chest x-rays are taken for the purpose of detecting undiscovered tuberculosis, but an outcome measure of years of extended life is too costly to be used and even case findings come late. And, as any learning paradigm indicates, the cue becomes derivatively valued. Just as column-inches in newspapers become a measure of health education, independent of readership or influence, so the number of $\mathrm{X}$-rays becomes a measure of program success independent of findings or effect. Now there is epidemiological evidence that the case-finding rate increases with depth of penetration, i.e., the greater the proportion of a population $\mathrm{x}$-rayed the higher the case rate, which is quite in accord with the fact that penetration is inversely related to status. It is traditional to start a campaign with the mayor, and it is seldom that the last wino is gotten. Therefore, from a basis much nearer the benefit, the $\mathrm{x}$-rays should be weighted as some direct function of the order obtained. Leaving such fine points of genuine validation 
aside, however, what we found was that although a target population was defined and the estimated number used as denominator, the numerator was all $\mathrm{x}$-rays taken on people in or out of the defined population. In the ensuing argument, which was lengthy and based on the presumed equal value of every film taken, we found that we were arguing with a United States Public Health Service manual. Meanwhile, $\mathrm{x}$-rays were pursued hither and yon. Agreement on objectives between practitioners and research people is important, and difficult, with the populace as bystanders, but they are affected.

Another related factor under the same heading of hidden assumptions, in the same study, concerned the procedures of "community organization." This was a social science model and, therefore, not to be questioned. However, both words may be questioned and the phrase is somewhat self-contradictory. If a community exists, it will possess organization, and the procedure is more nearly that of community mobilization, bending it to our purpose; the problem is to find the organization gatekeepers. If we search, we find, but if we look in the dark we stumble over things rather than discover, demonstrate, or document them. Community leaders can always be found, particularly if we ask those who might be. But who is following? Note that we are now, possibly, being blinded by our own view. It is very difficult to get and keep the subjects in mind, particularly when doing good.

Note also that when a social situation is deemed to demand intervention, there is an implication of things not working according to plan or belief. Functionalist doctrine does not work on dysfunctional situations. There is very likely to be some detachment of the group needing the special help called intervention. Whether this attains all of the properties associated with alienation is another matter, but when a social structure crumbles, as with steel, neat theories of crystallization must give way to hypotheses concerning flaws. When the economic system is not producing higher wages but unemployment, and when the political system does not redress the problems, industrial leaders and elected officials may not be the key to the organization of those with whom or on whom we want to work. If they trust anyone it may be deviants corresponding to their deviation. Suffice it to say that the leaders found in the rather non-community in which the $\mathrm{x}$-ray program was conducted did not produce crowding at the machines, and those they did lead into the vans were likely to have had other $x$-rays previously.

The tuberculosis $\mathrm{x}$-ray campaigns have now been dropped, since the benefits of treated cases may not outweigh the risk involved in exposure to $\mathrm{x}$-rays. Herein lies a real warning concerning possible untoward effects of intervention and the difficulty of finding unalloyed goods. Unstudied side-effects can be as disastrous socially as they are with drugs. In fact, the calls for social intervention today are frequently in regard to the effects of yesterday's cures.

Another pair of assumptions hit me low blows personally in another study, of public response to peacetime uses of atomic energy. ${ }^{\circ}$ One was technical and conerned the structure of our questionnaire. With reasonably developed theory, the funnel structure assumes a coherent subject matter approached in Aristotelian fashion through its genus, thus defining the subject in the process of questioning and securing the benefits of beginning with easy generality and developing reminiscence before getting into the sticky details. At that time, atomic energy had little coherence for the general public; indeed, a little thought indicated it had little for all nonphysicist professionals involved. Again, neat reliance on usual procedures did not work for the unusual. We generated a new generalization: the 
structure of the interview had to correspond to the structure of thought of the respondents. Again, our public changed us in time to be able to reflect their views more clearly.

One little related point should perhaps be emphasized. Initially, it was difficult to get people to discuss peacetime uses of atomic energy because the bomb intruded. As good professionals, we were able to circumvent this by a "drainage" question and pursue our course to what the Atomic Energy Commission was interested in. This time we didn't pick up the voice of the people. Nonintervention has its moral qualities, too. Sins, like statistical errors, are dichotomized into the classes of omission and commission. I should add here that a similar problem arises in the health field. People persist in telling us how illness hurts and disrupts their lives when we're trying to seek out diagnoses and services. True, we hope that our findings will shorten the hurt and lessen the disruption, but occasionally on a dark night the thought arises that this objectivity carried over into intervention is the problem. The bureaucratization of social relations is one of the things that hurts. This approach could keep us in business forever, unless those being intervened upon decide to intervene.

The second major, i.e., technical, issue in this study reminded us of the relativity of terms. As a social psychologist I pride myself on knowing how the various other aliquots live and think. I may know more than many; nevertheless, I occasionally learn - the hard way. Obviously, we were concerned with the dangers of atomic energy. I was not prepared by desk work, and at that time I didn't know as much about industrial accidents to have respondents, fortunately in a pretest, tell me that the place they worked in blew up about every six months. We say that our students or our colleagues blow up from time to time, but this does not really give us scale points within which to place many industrial workers' views of relative danger. If they say atomic energy isn't very dangerous to work with, what does it mean in willingness to work and lost lives?

Recently, research itself has come into question in many ways. Certainly, the numbers of persons following people around on Indian reservations and in ghettos may well raise issues. Placing a new reservoir over an old cemetery, or rehabilitating Navahos to sit on chairs but not ride, is not viewed as improvement. ${ }^{7}$ Telling people to do things they cannot possibly accomplish because of time, money, or distance barriers is grossly ineffective. These are just the results of ignorance, although they do not lead to bliss. Much worse is the callousness of older studies, now written up in the newspapers, using persons of low status as guinea pigs. There is resentment at being pawed over as "teaching material." A ghetto research institute is not now considered local progress. We have a legacy to contend with that we have to deal with and should not contribute to. And it is not just our morals that need looking at. It is difficult to foresee effects or anticipate needs.

Recently, the prize case, made the news again, although again we depend on journalists or discussions and mimeographed statements rather than research reports for our information. I refer to the intervention in Mound Bayou, Mississippi, to establish a health center, beginning with maternal and child health care services. $^{8}$ The well-intentioned team was not prepared to find that hunger was the big problem, and that while there were many health problems, food was more important than medicine. Fortunately, the group coming in learned fast, and reoriented, but the consequent local control of the project is, as I read it, what is now causing the trouble. Whose criteria of success do we use, those of the intervenors or of their public? That they may well be different, I have tried to indicate above. In poverty programs, is success to be judged by quiet in the ghetto 
or by increased pressure from the subjects, or by what and by whom? These are metaresearch questions and they predetermine the results.

Thus far, I have tried to raise the larger questions of approach and of design that can determine whether an entire project fails or has some chance of success, socially and intellectually. Many of these issues are associated with the views held by researchers about the subjects (and vice versa) and their correctness as a basis for operating and interacting. Within the tripartite relators, however, there is another source of difficulty in relations between operating personnel and research persons. The practitioners are trying to get something done, and the researchers to study or document what is being done. There are plenty of opportunities for misunderstanding and cross-purposes, particularly because these two groups have different social functions. If scientists and humanists be two subcultures, practitioners are a third. Within psychology, the difficulties of accommodating research and clinical psychology may form a base for understanding the misunderstandings. Certainly we can share goals, but we also get in one another's way. The researcher wants to take time to do a good job, the practitioners to get something done; and timetables can be a terror. Is it necessary to do a preliminary study to get a base line? To get precise measures, yes; but is this the objective, or improvement of the situation? Subjects are prone to side with practice; they want their obvious needs met. It really does not require an elaborate study to determine gross need, but it may well require some effort at quantitative data to determine whether what was done made a difference. What is done may not correspond to objectives established in planning. Feasibility is a key word with operators. It even determines many research sites and subjects, although we prefer to believe that scientists are more principled. The best that I've been able to achieve so far in developing a model of this is in statistical terms, which do have research implications. Scientists typically operate on low risk levels for Type I errors; we don't want to be found wrong. Practitioners take greater risks; they want to be right. When they know of it, they prefer to minimize Type II errors. Omission is a greater problem for them than commission. If you finally work something out, the false starts will be forgotten. Aside from making the real value differences underlying this more apparent, I would like to suggest a compromise we may make that may well be more nearly optimal for the total process. Perhaps in this type of research we might relax our stringent alpha level to ten percent or so, in the interest of not missing promising leads. In a practical situation, it is not statistical significance that should be the guiding principle, but the reduction in total variance. How well we really understand what is going on, totally, is more important than whether we are very certain we've explained what may well be a tiny piece. This is a small contribution to what we need badly, a theory of practice, but it may stimulate someone to work further.

I am assuming that the operating people and the research personnel are distinct. Although personality theory isn't up to proving it, I think the roles with differing values are too distinct for easy incorporation into one person, and what is said of the lawyer who argues his own case or the physician who treats himself may be true here, too.

Numerous problems other than timetables can arise. It is sometimes very difficult to find out in specific terms what the practitioners are going to do. The successful, which may not be the same as the good, administrator prefers not to commit himself to a precise course of action because he is very aware of the trial and error process involved. He will handle the problem; he will do what is necessary. This does not make for a neat set of hypotheses, except as a complex process 
model. Perhaps we have to achieve this; it appears necessary to understand medical practice, and it may be intrinsic to practice in general. Teaching appears to be like this: there is no one superior way, but we must be prepared to try what fits the students and this may differ among students. All of this may look like, and sometimes it is, a case of saying one thing and doing another. And here we are trying to pin the man down. He may have a number of schemes up his sleeve to try, and we want a neat experimental design to fit our statistical procedures. We may have to adopt multiple working hypotheses and incorporate them in a more complex, branched decision model which uses conditional probabilities from observation and feed back from subjects rather than a factorial imposition of all procedures on all known kinds of subjects. The subject may say, "It still hurts, Doc," and good data on the inefficacy of the treatment are not satisfactory to him however valuable they may be. Unexpected or adventitious results may be satisfactory but very difficult to account for. Hawthorne and placebo effects are well known, and the very efforts we make to accommodate to and understand the practitioner may introduce effects for which double-blind procedures are necessary in medicine. We may try to understand, but we cannot get overly sympathetic. Note that every degree of independence on our part is a threat to the practitioner, since we are checking him. This is a tough, subtle, and delicate relationship. It can well involve the subjects who try to get us on their side. We become ombudsmen or political commissars or grievance agents, and trying to explain ourselves to subjects as information processors is difficult because it is unsatisfactory to them. Again, an optimum balance requires a quantitative model, which I do not have. A qualitative outline may, however, keep us from the extremes, which may be disastrous, but we also must keep from oscillating as we well might with high risks, high uncertainty, and highly amplified feedback.

There is a third set of considerations that I pass over lightly, since the literature on direct interaction with subjects is reviewed as interviewing problems, although not presented as quantitative models either. ${ }^{9}$ Here again, however, our assumptions and prejudices come into play. Subjects and respondents can sense, and do respond to, condescending or other attitudes. From the general-how can people live this way? - to the more specific-they must be ashamed to tell me their income-we establish conditions for self-fulfilling prophecies. Compliance is the great enemy of truth in interviewing. Any hint about what we want, any departure from complete permissiveness and acceptance is a clue that may condition the response. Of course, in more extreme cases we do not get submissive compliance; we may get no answers or evasions, or we may be thrown out. How the research is presented is quite important. The auspices can be critical, if meaningful, although our agency is totally unknown to the subject more frequently than we like to think. However, promises to help people are dangerous, if impelling, motives. Ghetto residents are no longer so sure the promises have been fulfilled sufficiently to constitute continuing premises. But we are a presence to the subjects, and what we represent to them may make a difference, and this can vary from being seen as representatives of the establishment, to nosy busybodies, to sympathetic listeners and communicators. We may not be overly helpful, but we can establish a useful and valuable role, if we explain ourselves honestly and devote ourselves seriously to the needs and satisfactions of the subject.

Finally, I cannot help recalling, although I do not intend to dwell on them in the way we have to live with them, certain general long-term effects of research on our subjects. We, in the sense of the scientific investigators with whom we would like to identify, have interacted with our subjects with notable effect. At 
first, people were fearful of the profound, mysterious and powerful phenomena that were investigated and of results challenging their beliefs. Later, a hopeful and trusting people supported research on the basis of its accomplishments for them. Now, there is renewed doubt and distrust as unforeseen and unwanted effects become apparent. As we work on these and wish to share in the credit for old accomplishments we must accept some of the blame a!so, and so act. It is toward this heightened awareness of the conditions and responsibilties of intervention that $I$ have tried to direct myself and all of you.

\section{References}

1. Goldmann, Franz \& Evert A. Graham, 1954. The Quality of Medical Care Provided at the St. Louis Labor Health Institute. Labor Health Institute. St. Louis, Mo.

2. Wandelt, Mabel A. 1954. Planned versus incidental instruction for patients in tuberculosis therapy. Nursing Rev. 3: 52-59.

3. Pratt, Lors. 1956. How do patients learn about disease? Social Problems 4: 29-39.

4. Bogg, Richard A. 1971. Alienation and Medical Care in a Public Setting. Unpublished Ph.D. dissertation. Univ. of Michigan. Ann Arbor, Mich.

5. Metzner, Charles A. \& Gerald Gurin. 1960. Personal Response and Social Organization in a Health Campaign. School of Public Health. Bureau of Public Health Economics. Res. Ser. No. 9. Univ. of Michigan. Ann Arbor, Mich.

6. Fisher, Burton R., Charles A. Metzner \& Benjamin J. Darsky. 1951. Public Response to Peacetime Uses of Atomic Energy. I, II. Survey Research Center, Univ. of Michigan. Ann Arbor, Mich.

7. McDermott, W., K. Deuschle, J. Adair, H. Fulmer \& B. Loughlin. 1960. Introducing modern medicine in a Navaho community. Science 131: 197-205, 280-287.

8. Hali, Richard. 1969. A Stir of Hope in Mound Bayou. Life Magazine. 66: 66-70.

9. Kahn, Robert L. \& Charles F. Cannell. 1959. The Dynamics of Interviewing. Wiley. New York, N.Y.

\section{Discussion}

DR. IVERSON: Dr. Bunker regarded experimental research as a second level of investigation. I'm not quite sure where you would put experimental research.

DR. METZnER: I think experimental design is fundamental to doing any kind of research. The process of validating our conclusions that is embodied in this is, I think, a paradigm that we have to follow to a great extent, and there are dangers in departing from it. What I did want to call attention to are the difficulties of implementing it, which $I$ think are also great.

DR. IVERSON: And to be aware of those difficulties.

Dr. Metzner: Occasionally, we have to substitute caution in conclusion for rigor in logic. 